\title{
Spatial dynamics of urban populations of Lutzomyia longipalpis (Diptera: Psychodidae) in Caxias, State of Maranhão, Brazil
}

\author{
Maria do Desterro Soares Brandão Nascimento ${ }^{[1],[2],}$ Maria Helena Silva ${ }^{[1],[2],}$ \\ Graça Maria de Castro Viana ${ }^{[1],[2], ~ F r a n c i s c o ~ S a n t o s ~ L e o n a r d o ~}{ }^{[1],[2],}$ \\ Geusa Felipa de Barros Bezerra ${ }^{[1],[2]}$, Antonia Suely Guimarães e Silva ${ }^{[1],[2],}$ \\ Valéria Cristina Pinheiro Soares ${ }^{[1],[2],}$ Silma Regina Ferreira Pereira ${ }^{[1],[2],}$ \\ José Manuel Macário Rebêlo ${ }^{[1],[2]}$ and Reginaldo Peçanha Brazil ${ }^{[3]}$
}

[1]. Departamento de Patologia, Universidade Federal do Maranhão, São Luis, MA. [2]. Centro de Estudos Superiores de Caxias, Universidade Estadual do Maranhão, Caxias, MA. [3]. Instituto Oswaldo Cruz, Fundação Oswaldo Cruz, Rio de Janeiro, RJ.

\begin{abstract}
Introduction: In this paper, we report the ecology of Lutzomyia longipalpis in Caxias City, located in the eastern part of State of Maranhão, Brazil and highlight its seasonal and geographical distribution by environment. In addition, we discuss natural Leishmania infection and its relationship with visceral leishmaniasis. Methods: Between September 2007 and August 2009, the collection of sandflies was performed using Center for Disease Control (CDC) light traps from 15 houses in 5 selected neighborhoods. Results: Lutzomyia longipalpis was present in all zones of the city. We also found that Lu. longipalpis was regularly detected both inside and around the house, predominantly in outdoor areas. In urban areas, Lu. longipalpis was present in both the dry and rainy seasons, with a higher density present in the latter. One female specimen of Lu. longipalpis was observed to have natural Leishmania infection. Conclusions: The presence of $L u$. longipalpis was observed throughout the year during 2 seasonal periods, with a predominance in the rainy season. A low rate of natural Leishmania infection was observed in urban areas during the rainy season.
\end{abstract}

Keywords: Lutzomyia longipalpis. Distribution. Natural infection. Urban areas. Maranhão.

\section{INTRODUCTION}

Leishmaniasis is considered a serious public health problem and is among the 6 most important infectious and parasitic diseases. This infection manifests in different clinical forms, including visceral leishmaniasis (VL) and cutaneous leishmaniasis (CL), as a result of the diversity of the parasites that affect the human population ${ }^{1}$.

Visceral leishmaniasis is a notified disease that has become a major public health problem in Brazil. In Maranhão, Brazil, the first records of autochthonous human cases in urban areas occurred in 1982 on the island of São Luis, which is located in the northern region of the state. Thereafter, an increasing number of infections in urban areas led to the capital being classified as an endemic area².

\footnotetext{
Address to: Dr. Reginaldo Peçanha Brazil. Laboratório de Doenças Parasitárias/ IOC/FIOCRUZ. Av. Brasil 4365, 21040-900 Rio de Janeiro, RJ, Brasil.

Phone: 5521 2562-1229

e-mail: rpbrazil@ioc.fiocruz.br

Received 26 July 2013

Accepted 7 October 2013
}

Studies on the island of São Luis, State of Maranhão, demonstrated that Lutzomyia longipalpis is the most frequently encountered species. This phlebotomine is well adapted to living alongside humans and domestic animals ${ }^{3}$ and is therefore the suspected vector in most cases of VL .

Since the year 2000, the early spread of VL cases into the interior of the state led to an increase in the incidence of the disease between 2000 and 2004. Data from Sistema de Informação de Agravos de Notificação (SINAN) and the Epidemiological Surveillance of Caxias have shown that the number of cases in this city has remained relatively constant over the past 9 years, with a total of 626 cases during this period, which demonstrates the local endemicity of this state. Currently, VL is characterized as widespread in State of Maranhão, while it is characterized as endemic in the Caxias municipality.

The urbanization of VL is evident in municipalities where peripheral regions and households are significantly affected by the presence of Lu. longipalpis. In particular, 4 of 43 districts have been classified as areas of intense transmission ${ }^{5}$.

Depending on the area analyzed, climatic factors, such as temperature and rainfall, can affect various aspects of the sandfly population ${ }^{6}$. Thus, local knowledge of the species and aspects that modify the frequency of vectors is important for planning prevention strategies and interventions ${ }^{7}$. 
Considering the urbanization of VL and the importance of understanding the sandfly fauna, especially in endemic regions, we sought to study the ecology of Lu. longipalpis in Caxias City, with an emphasis on natural infection, seasonal distribution, spatial environments, and their relationship to VL. Thus, the goal of this study was to improve the knowledge about the occurrence of VL in this location, as well as to provide information for epidemiological monitoring of the municipality and vector and disease control.

\section{METHODS}

\section{Area of study}

Caxias is located on the eastern side of the State of Maranhão. This area presents a warm, semi-humid, and semi-arid climate with vegetation typical of the savanna and savanna-caatinga contact zone ${ }^{8}$. In addition, this region is characterized by a hot, rainy season that lasts for the first six months of the year (January/June). Caxias is located at latitude $04^{\circ} 51^{\prime} 32^{\prime \prime} \mathrm{S}$ and longitude $43^{\circ} 21^{\prime} 22^{\prime \prime} \mathrm{W}$, and has an altitude of $66 \mathrm{~m}$, an area of $5,150.647 \mathrm{~km}^{2}$, and a population (estimated in 2010) of 155,129 inhabitants ${ }^{8}$.

\section{Sandfly collection}

Sandflies were captured monthly, from September 2007 to August 2009, between the hours of $6 \mathrm{pm}$ to $6 \mathrm{am}$ using miniature Centers for Disease Control (CDC) light traps. Fifteen houses were selected based on the record of human VL cases. The City of Caxias was subdivided into urban areas, consisting of 3 houses per zone, such that the houses were located in the northern (Seriema), southern (Itapecuruzinho), eastern (João Viana), western (Trezidela), and central (Refinery) neighborhoods. In each house, 2 traps were installed ( 1 in a peridomecile chicken coop and/or pig pen and another inside the house), and the traps functioned continuously for $12 \mathrm{~h}$ on 3 consecutive days.

All species were identified with the aid of the identification key proposed by Young and Duncan to separate Lu. longipalpis from other sandfly species ${ }^{9}$. Specimens were kept dry at $4^{\circ} \mathrm{C}$ prior to molecular analysis. The meteorological data were obtained from the Meteorological Institute of the Universidade Estadual do Maranhão.

To evaluate the natural infection of sandflies, individual sandflies were separated into $1.5-\mathrm{ml}$ plastic tubes, and their contents were processed to extract DNA from each individual, following the protocol described by Mukhopadhyay et al. ${ }^{10}$ and modified by Pereira ${ }^{11}$. Engorged females or those with any trace of blood were not used to avoid the presence of parasite DNA rather than natural infection. Samples were heated in a water bath for $10 \mathrm{~min}$ at $95^{\circ} \mathrm{C}$ in $20 \mu \mathrm{l}$ of sodium chloride tris-ethylenediamine tetra-acetic acid (STE) buffer $(0.1 \mathrm{M} \mathrm{NaCl}, 10 \mathrm{mM}$ Tris-HCl, $\mathrm{pH}$ 8.0, $1 \mathrm{mM}$ EDTA). The samples were then macerated, and STE was added to make the final volume $50 \mu \mathrm{l}$. The samples were again heated for $10 \mathrm{~min}$ at $95^{\circ} \mathrm{C}$ and then centrifuged at $12,000 \mathrm{rpm}$ for $2 \mathrm{~min}$. From the final extraction product, $20 \mu 1$ of the DNA-containing supernatant was transferred to a new tube and stored at $-20^{\circ} \mathrm{C}$ prior to polymerase chain reaction (PCR) analysis. The extracted Leishmania DNA was amplified using the primers $5^{\prime} \mathrm{GGG}(\mathrm{G} / \mathrm{T})$ AGGGGCGTTCT(G/C)CGAA3' and 5'(G/C)(G/C)(G/C)(A/T) CTAT(A/T)TTACCAACCCC3', which amplify a fragment of 120 base pairs in the region of the of kinetoplast minicircle (kDNA). The reaction mixture was composed of $4 \mu$ l of genomic DNA, $1 \times$ PCR buffer, $1 \mu \mathrm{M}$ of each primer, $1.5 \mu \mathrm{M} \mathrm{MgCl}{ }_{2}$, $200 \mu \mathrm{M}$ of each dNTP (Invitrogen), $1 \mathrm{U}$ of Taq DNA polymerase (Invitrogen), and $8.8 \mu \mathrm{l}$ of sterile water. DNA amplification was performed in a thermocycler (MJ Research PTC-100/Peltier Thermal Cycler, MJ Research INC., Waltham, Massachusetts, USA), with denaturation conditions of $94^{\circ} \mathrm{C}$ for $5 \mathrm{~min}$, followed by 14 of 94 cycles at $30^{\circ} \mathrm{C}$ for $30 \mathrm{~s}, 55^{\circ} \mathrm{C}$ for $30 \mathrm{~s}$, and $72^{\circ} \mathrm{C}$ for $45 \mathrm{~s}$, with a final extension of $72^{\circ} \mathrm{C}$ for $10 \mathrm{~min}$. For each reaction subjected to PCR amplification, we used a positive control (reaction mixture + DNA of Leishmania infantum) and a negative control (reaction mixture + sterile water). The first reactions were carried out with pooled DNA from 10 individuals. After amplification for the genus Leishmania, further reactions were performed, one for each individual. In samples where there was no amplification, the PCR was repeated with the same pool. After confirmation of the previous result, an inhibition test was performed in which the negative samples were submitted to the same conditions of PCR, with the addition of $1 \mu$ of Leishmania DNA. All positive samples were confirmed by repeating the reaction. Contamination of exogenous DNA was avoided by careful handling of pipettes and reagents. For detection and analysis of the PCR products, amplicons were submitted to electrophoresis on $2 \%$ agarose gels, and the bands were visualized under ultraviolet light after staining with ethidium bromide. After electrophoresis, the gels were photographed and analyzed. We were able to determine the actual infection rate of Lu. longipalpis by Leishmania because the samples were analyzed individually. This rate was calculated using the following formula: [number of positive individuals $\times$ $100 /$ total number of individuals].

\section{RESULTS}

In total, 1,363 specimens of Lutzomyia longipalpis (899 males and 464 females) were captured, following $4,320 \mathrm{~h}$ of trapping. Sandflies predominated in the central zone, with 485 individuals trapped (35.5\%), followed by the eastern zone [377 $(27.6 \%)]$, the western zone [244 (17.9\%)], the northern zone [210 (15.4\%)], and the southern zone [47 (3.4\%)] (Table 1). Among the total number of $L u$. longipalpis specimens, $49.5 \%$ were collected inside of houses (intradomicile), and 50.5\% were collected in the areas surrounding the houses (peridomicile). There were larger numbers of male specimens $(66.7 \%)$ collected than females (33.3\%).

Upon analyzing the seasonality over a period of 2 years, we observed a predominance of Lu. longipalpis in the rainy season $(62.9 \%)$ compared with the dry season $(37.1 \%)$. The highest densities of Lu. longipalpis in the first year of the study period occurred in January, February, and July, whereas the highest 
TABLE 1 - Frequency of Lutzomyia longipalpis by neighborhood in an urban area of Caxias, State of Maranhão, from September 2007 to August 2009.

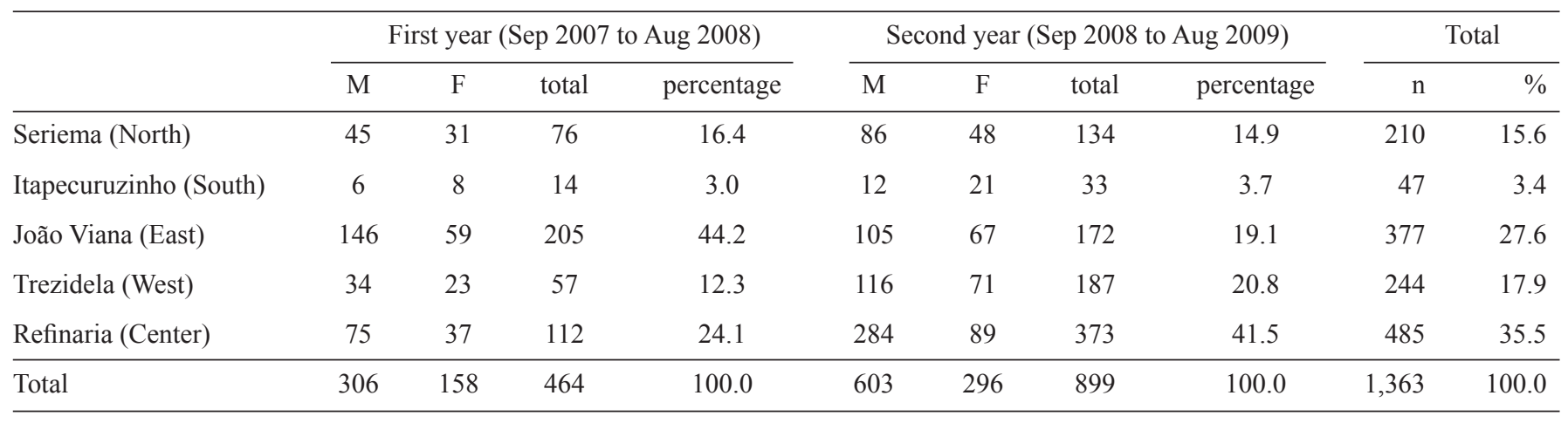

M: male; F: female.

densities in the second year were observed in January (Figure 1). In the first year of the study, from September 2007 to August 2008 , the average temperatures during the rainy season ranged between 25 and $28.8^{\circ} \mathrm{C}$, and the mean rainfall varied between 7.25 and $295.00 \mathrm{~mm}^{3}$. During the dry season of this period, the average temperatures ranged from 25 to $29.4^{\circ} \mathrm{C}$, while the mean precipitation values ranged from 0.00 to $66.00 \mathrm{~mm}^{3}$ (Figure 2).

In the second year of the study, the average temperatures during the rainy season, from September 2008 to August 2009, ranged from 25.2 to $28^{\circ} \mathrm{C}$, while the mean rainfall values varied between 27.00 and $376.00 \mathrm{~mm}^{3}$. In the dry season during this period, the average temperatures ranged from 27.7 to $29.4^{\circ} \mathrm{C}$, and the highest temperature $\left(29.4^{\circ} \mathrm{C}\right)$ was observed in the month of November. In addition, the mean precipitation values ranged from 0.00 to $79.25 \mathrm{~mm}^{3}$ (Figure 3).

To determine the rate of natural infection, 130 females were analyzed, $80(62 \%)$ from the rainy season and $50(38 \%)$ from the dry season. Although 464 females were captured, only 130 specimens were used in this study due to improper preservation. The initial amplification reactions (PCR) were performed for 10 pooled females per season, totaling 13 pools of Lu. longipalpis (8 pools from the rainy season and 5 pools from the dry season). Of these 13 pools, only 1 pool from the rainy season demonstrated positive results (Figure 4). Performing additional PCRs for each individual in this positive pool revealed that only 1 female was infected. These data show that the rate of actual infection of Lu. longipalpis was $0.76 \%$ among all sandflies analyzed.

\section{DISCUSSION}

In this study, Lutzomyia longipalpis was present in all 5 urban areas examined, which indicates the great adaptability of this species in urban environments ${ }^{1,12}$ and further explains the occurrence of VL cases in all urban areas studied. There was a predominance of the vector in the central area of the city compared with the southern area, which is the most conserved area. This result demonstrates that the transmission of $\mathrm{VL}$ in Brazil has undergone a process of urbanization, involving transition of the disease distribution from an almost entirely rural

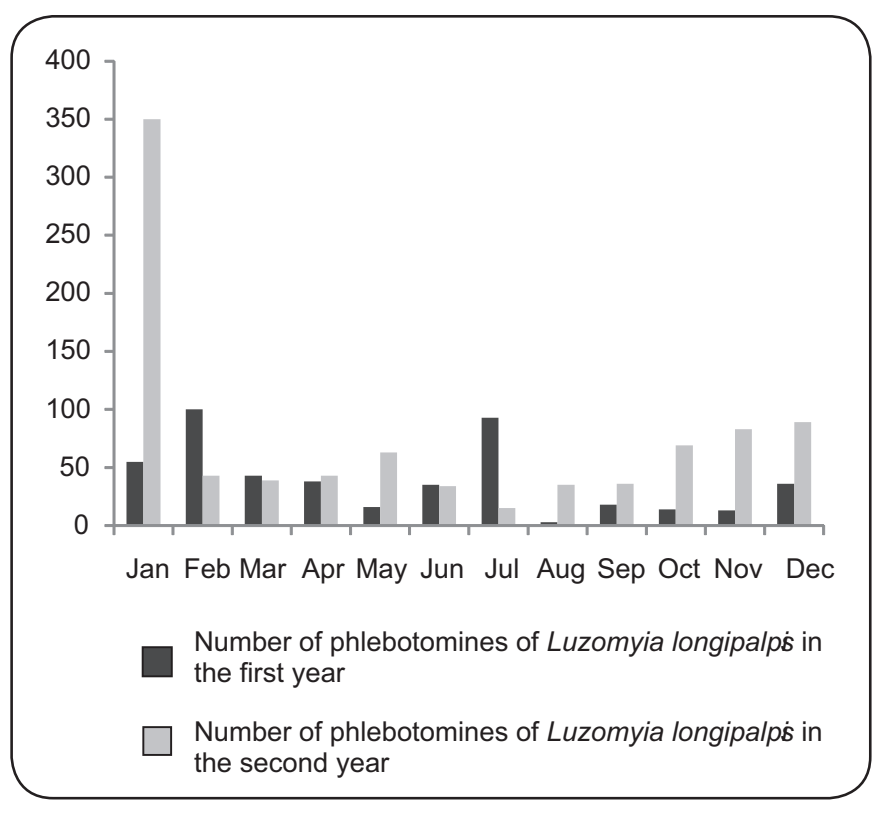

FIGURE 1 - Frequencies of both genders of Lutzomyia longipalpis during the two study periods.

environment to larger urban areas ${ }^{13}$. There was also a slightly higher proportion of specimens captured in peridomiciles of the residences examined, and similar results in Maranhão State have revealed the predominance of sandflies in peridomestic areas $^{12,14}$. In addition, the observed predominance of males may be explained by the attraction exerted by light traps and the aggregation behavior in environments where females are in search of food ${ }^{15}$. During the 2 years of this study, no strong evidence for seasonality was observed; Lu. longipalpis was present all year but demonstrated a peak in incidence at the beginning of the rainy season, as previously observed in Campo Grande, State of Mato Grosso do Sul, Brazi $1^{16}$.

Natural infection of Lutzomyia longipalpis was detected, for the first time, in the City of Caxias at a rate of $0.76 \%$. This low natural infection rate follows the pattern previously identified in Maranhão and other Brazilian states ${ }^{11}$. However, 


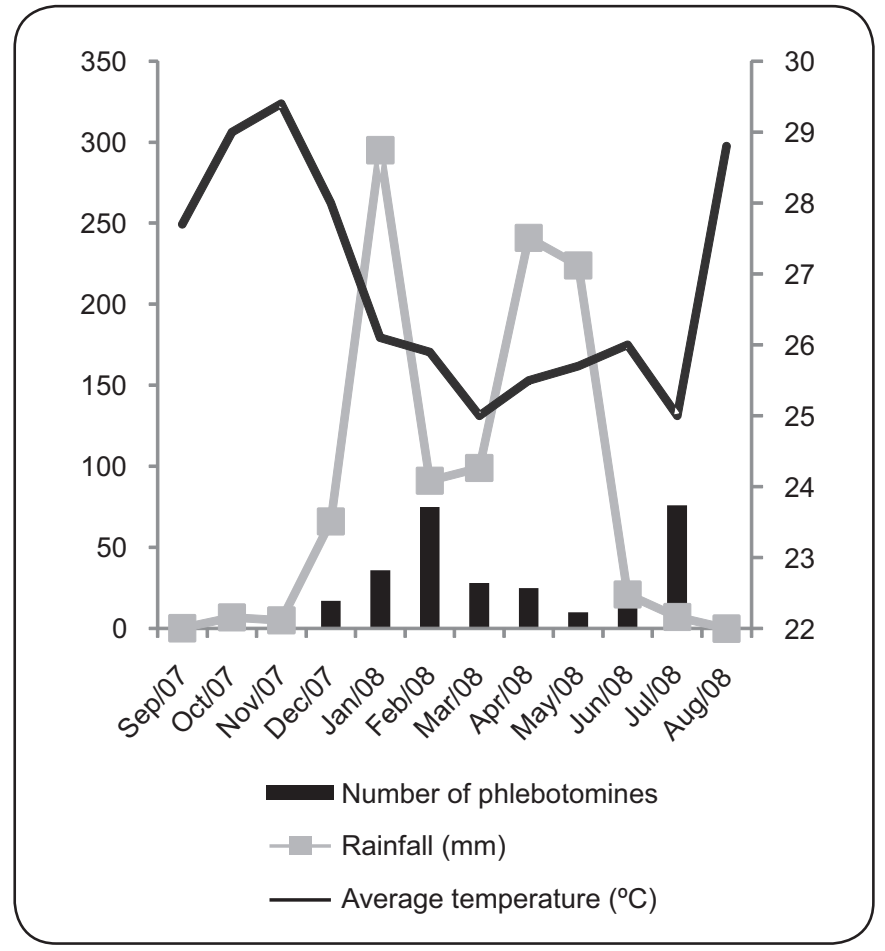

FIGURE 2 - Monthly distribution of the frequency of Lutzomyia Longipalpis and the average temperature and rainfall from September 2007 to August 2008 in Caxias, State of Maranhão, Brazil.

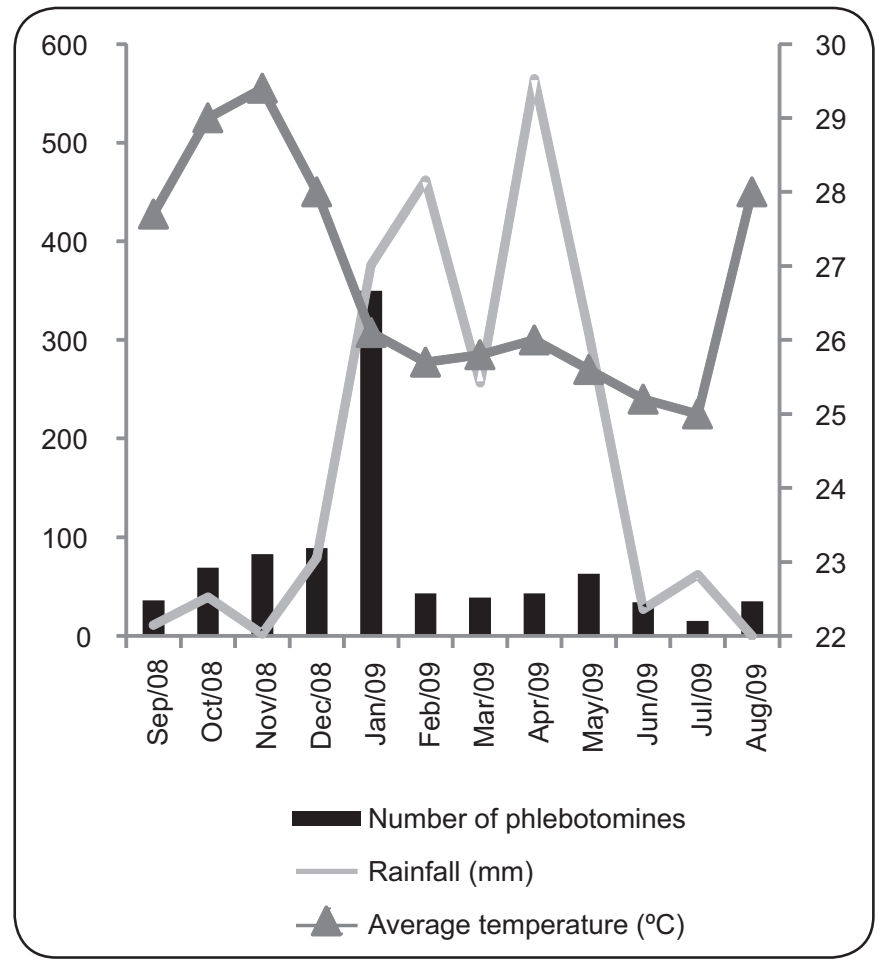

FIGURE 3 - Monthly distribution of the frequency of Lutzomyia Longipalpis and the average temperature and rainfall from September 2008 to August 2009 in Caxias, State of Maranhão, Brazil.

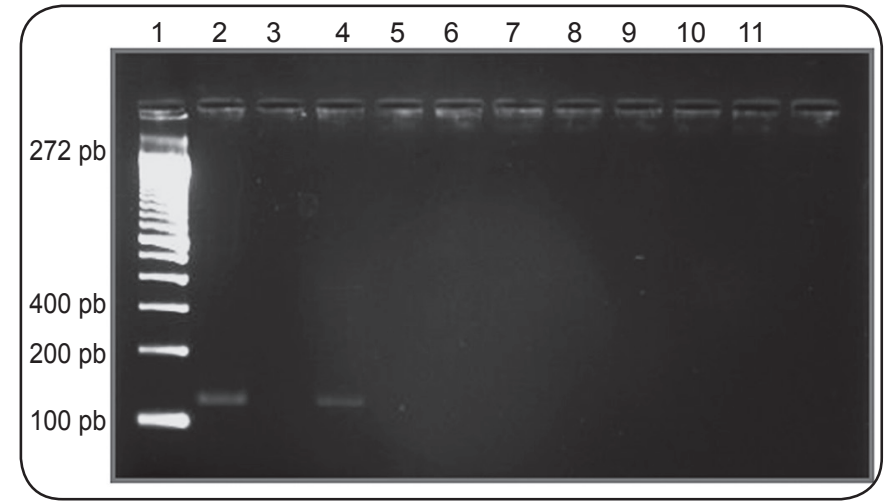

FIGURE 4 - The amplification products of the genus Leishmania, performed on pools of female Lutzomyia longipalpis specimens collected during the rainy season, shown on $2 \%$ agarose gels stained with ethidium bromide. Lane 1: molecular weight marker; Lane 2: positive control; Lane 3: negative control; Lane 4: positive pool; and Lanes 5, 6, 7, 8, 9, 10 and 11: negative pools.

this low rate cannot be considered a definitive result because only a small number of females were examined; therefore, this result should be interpreted with caution. Nevertheless, it seems that this infection rate was sufficient for maintenance of the disease, considering the high rates of infection in the city and the presence of Lu. longipalpis in intradomicile locations. This result also supports the findings of $\mathrm{Nascimento}^{2}$, in which a mathematical model of the transmission dynamics of VL on the island of São. Luis revealed that vector control was an effective approach for combating disease and that a low infection rate in the vector is sufficient to maintain endemicity. As in other studies conducted in State of Maranhão, $L u$. longipalpis was distributed throughout the year ${ }^{3}$. A similar distribution has also been observed in other states, such as Ceará, Bahia, Mato Grosso do Sul, and Minas Gerais ${ }^{17,18}$. The abundance of $\mathrm{Lu}$. longipalpis in intra- and peridomestic environments, together with the identification of natural infection with Leishmania and human VL cases, demonstrates that, in urban areas, this species meets the essential criteria for a competent vector ${ }^{1}$.

The distribution pattern of the vector in urban areas can likely be explained by the degradation of the environment and the presence of humans as a potential food source. Moreover, the distribution of this vector was observed throughout the year in 2 seasonal periods, with a predominance in the rainy season. Using PCR, we detected natural infection of Lu. longipalpis following identification of a single positive female collected during the rainy season. Therefore, it should be stressed that a low rate of natural infection is sufficient to maintain the endemicity in the region.

\section{CONFLICT OF INTEREST}

The authors declare that there is no conflict of interest.

\section{FINANCIAL SUPPORT}

Conselho Nacional de Desenvolvimento Cientifico e Tecnológico (CNPQ): Edital MCT/CNPq/MS-SCTIEDECIT 25/2006. 


\section{REFERENCES}

1. Lainson R, Rangel EF. Lutzomyia longipalpis and the eco-epidemiology of American visceral leishmaniasis, with particular reference to Brazil: a review. Mem Inst Oswaldo Cruz 2005; 100:811-827.

2. Nascimento MDSB. Epidemiologia da leishmaniose visceral na Ilha de São Luís-Maranhão, Brasil: análise da dinâmica da transmissão e dos fatores de risco relacionados ao desenvolvimento da doença [Doctors Thesis]. [São Paulo]: Escola Paulista de Medicina, Universidade Federal de São Paulo; 1996.

3. Rebêlo JMM, Oliveira ST, Silva FS, Barros VLL, Costa JML. Flebótomos (Diptera: Psycodidae) da ilha de São Luís, zona do Golfão Maranhense. Rev Soc Bras Med Trop 1999; 33:247-253.

4. Ryan L, Brazil RP. Leishmania infections in Lutzomyia longipalpis (Diptera: Psychodidae) on the island of São Luis, Maranhão State, Brazil. Mem Inst Oswaldo Cruz 1984; 79:383-384.

5. Sistema de Informação de Agravos de Notificação (SINAN). Ministério da Saúde. Tabulação de dados-TabNet. [Cited during the year of 2012, data from 2006 to 2008] Available at: http://dtr2004.saude.g.,ov.br/ sinanweb/index.php.name $=$ Tabnet $/$.

6. Macedo ITF, Bevilaqua CML, Morais NB. Sazonalidade de flebotomíneos em área endêmica de leishmaniose visceral no município de Sobral, Ceará, Brasil. Ciencia Animal 2008; 18:67-74.

7. Almeida PS, Minzão ER, Minzão LD. Aspectos ecológicos (Diptera: Psychodidadae) em área urbana do município de Ponta Porã, Estado de Mato Grosso do Sul. Rev Soc Bras Med Trop 2010; 43:723-727.

8. Instituto Brasileiro De Geografia e Estatística (IBGE). Cidades. [Cited 2011 August 10]. Available at: http://www.ibge.g.,ov.br/cidadesat/painel/ painel.php?codmun=210300\#/.

9. Young DG, Duncan MA. Guide to the identification and geographic distribution of Lutzomyia sandflies in Mexico, the West Indies, Central and South America (Diptera: Psychodidae). Mem Amer Ent Inst 1994; 54:1-881.

10. Mukhopadhyay J, Ghosh K, Braig HR. Identification of cutaneous leishmaniasis vectors, Phlebotomus papatasi e $P$. duboscqi using random amplified polymorphic DNA. Acta Tropica 2000; 76: 277-283.

11. Pereira YNO, Rebêlo JMM, Moraes JLP, Pereira SRFP. Diagnóstico molecular da taxa de infecção natural de flebotomíneos (Psychodidae, Lutzomyia) por Leishmania sp. na Amazônia Maranhense. Rev Soc Bras Med Trop 2006; 39:540-543.

12. Leonardo FS, Rebêlo JMM. Lutzomyia whitmani periurbanization in a focus of cutaneous leishmaniasis in the State of Maranhão, Brazil. Rev Soc Bras Med Trop 2004; 37: 282-284.

13. Brazil RP. Dispersion of Lutzomyia longipalpis in urban areas. Rev Soc Bras Med Trop 2013; 46:263-264

14. Barros VL, Rebêlo JMM, Silva FS. Flebotomíneos (Diptera, Psychodidae) de capoeira do município do Paço do Lumiar, Estado do Maranhão, Brasil. Área endêmica de leishmanioses. Cad Saude Publica 2000; 16:265-270

15. Oliveira AG, Galati EA, Oliveira O, Oliveira GR, Espíndola IA, Dorval ME, et al. Abundance of Lutzomyia longipalpis (Diptera:Psychodidae: Phlebotominae) and urban transmission of visceral leishmaniasis in Campo Grande, State of Mato Grosso do Sul,Brazil. Mem Inst Oswaldo Cruz 2006; 101:869-874.

16. Bray DP, Bandi KK, Brazil RP, Oliveira AG, Hamilton JGC. Synthetic sex pheromone attracts the leishmaniasis vector Lutzomyia longipalpis (Diptera: Psychodidae) to traps in the field. J Med Entomol 2009; 46: 428-434.

17. Deane LM. Leishmaniose visceral no Brasil. Rio de Janeiro: Serviço Nacional de Educação Sanitária; 1956.

18. Galati EAB, Nunes VLB, Dorval MEC. Estudo dos flebotomíneos (Diptera, Pychodidae), em área de leishmaniose tegumentar, no Estado de Mato Grosso do Sul, Brasil. Rev Saude Publica 1996; 115-128. 